\title{
Serum N-Terminal Telopeptide of Type I Collagen as a Biomarker for Predicting Bone Density Loss in Patients with Crohn Disease
}

\section{Natsuki Ishida}

Hamamatsu University School of Medicine

Tomohiro Higuchi

Hamamatsu University School of Medicine

Takahiro Miyazu

Hamamatsu University School of Medicine

Satoshi Tamura

Hamamatsu University School of Medicine

\section{Satoshi Suzuki}

Hamamatsu University School of Medicine

Shinya Tani

Hamamatsu University School of Medicine

Mihoko Yamade

Hamamatsu University School of Medicine

Moriya Iwaizumi

Hamamatsu University School of Medicine

Yasushi Hamaya

Hamamatsu University School of Medicine

\section{Satoshi Osawa}

Hamamatsu University School of Medicine

\section{Takahisa Furuta}

Hamamatsu University School of Medicine

Ken Sugimoto ( $\nabla$ sugimken@hama-med.ac.jp )

Hamamatsu University School of Medicine https://orcid.org/0000-0001-9586-1097

\section{Research article}

Keywords: N-terminal telopeptide of type I collagen, Crohn disease, osteoporosis, Z-score

Posted Date: September 28th, 2020

DOI: https://doi.org/10.21203/rs.3.rs-76103/v1 
License: (c) (i) This work is licensed under a Creative Commons Attribution 4.0 International License. Read Full License 


\section{Abstract}

Background:The serum N-terminal telopeptide of type I collagen (NTx) is significantly higher in patients with Crohn disease (CD) than in healthy individuals and patients with ulcerative colitis. This study aimed to investigate whether an elevated serum NTx level is a risk predictor of osteoporosis in patients with CD.

Methods: Based on whether the femoral Z-score decreased over a 2-year period, $41 \mathrm{CD}$ patients were divided into the $\Delta Z$-score $<0$ group (Z-score decreased) and the $\Delta Z$-score $\geq 0$ group (Z-score did not decrease). The risk predictors of a femoral Z-score decrease were examined. Furthermore, we investigated the correlations between the $\Delta Z$-score (which represents the change in the Z-score over a 2-year period) and the mean levels of biomarkers including the Crohn's Disease Activity Index (CDAl), serum albumin, Creactive protein, and bone metabolism markers (including NTx) measured initially (i.e., in our previous study) and 2 years later (present study). The relation between anti-tumor necrosis factor a (anti-TNF-a) therapy and serum NTx levels were also examined.

Results: Although there was no correlation between the mean CDAl and the $\Delta Z$-score, the mean serum NTx and albumin levels were significantly correlated with the $\Delta Z$-score $(P<0.01$ and $P=0.02$, respectively). Furthermore, the femoral Z-score tended to be lower in the anti-TNF-a administration group than in the non-administration group.

Conclusions: These observations indicated that an elevated serum NTx could be a useful marker for predicting a decrease in the femoral bone mineral density in CD patients. Anti-TNF-a therapy maintained an elevated serum NTx level, suggesting that treatment with anti-TNF-a may help control increased bone resorption in CD patients.

\section{Background}

Inflammatory bowel disease (IBD), which includes Crohn disease (CD) and ulcerative colitis (UC), is associated with a high incidence of osteoporosis [1-6]. Approximately $18-42 \%$ and $22-77 \%$ of the patients with IBD have osteoporosis and reduced bone mineral density (BMD), respectively [7, 8]. In fact, the risk of fracture is high in IBD patients, and the relative risk of all fractures is reported to be 1.41 (95\% confidence interval [Cl]: 1.27-1.56, $\mathrm{P}<0.001$ ) [9]. Because osteoporosis carries a fracture risk, prevention of osteoporosis in IBD is important because fractures significantly reduce the patient's quality of life.

Osteoporosis is diagnosed by measuring the BMD using dual-energy X-ray absorptiometry (DEXA), the results of which are presented as the Z- and T-scores [10-13]. Furthermore, biochemical bone metabolism markers are also used for evaluating the state of bone metabolism. These markers are classified into bone formation markers, which include bone-specific alkaline phosphatase (BAP) and the N-terminal propeptide of type I collagen; bone resorption markers, which include the $\mathrm{C}$ - and $\mathrm{N}$-terminal telopeptides (NTx) of type I collagen; and bone matrix-related markers, which include undercarboxylated osteocalcin (ucOC; related to vitamin $\mathrm{K}$ deficiency) [14-17]. 
Bone metabolism is also associated with the activity of proteases, including the matrix metalloproteinases, and with the disease activity matrix metalloproteinases in IBD [18-20]. Furthermore, IBD is associated with hypoalbuminemia due to malnutrition, which is independently associated with the risk of osteoporosis in the femoral neck, hips, and lumbar spine. A longer duration of hypoalbuminemia was reported to increase the risk of osteoporosis at the same anatomical site [21] and at different anatomical sites [22].

In a previous cross-sectional study [23], we examined the association between biochemical bone metabolism markers (namely BAP, NTx, ucOC, and 1,25-dihydroxyvitamin D [1,25-(OH) $\left.{ }_{2} \mathrm{D}\right]$ ) and bone density in IBD patients and reported that the serum NTx level, a biochemical marker predicting an increase in bone resorption, is significantly elevated in patients with CD receiving infliximab (IFX). However, in this study, the BMD and bone metabolism markers were examined in a single measurement, and we realized the need to investigate long-term changes in bone metabolism over time. Therefore, in this study, the BMD and bone metabolism markers were measured again 2 years after the initial measurement in the previous study, and the differences between them were evaluated.

\section{Methods}

\section{Aim, design, and setting}

We aimed to investigate whether elevated serum NTx level is a risk predictor of osteoporosis in patients with $\mathrm{CD}$. In this prospective study, we examined the significance of various bone metabolism biomarkers, including the serum NTx levels, in CD patients who were treated at the Hamamatsu University School of Medicine between July 2013 and February 2016 who were having a tendency for reduced BMD.

\section{Patients}

A total of 41 patients (34 male and 7 female) with CD were enrolled in this study. We selected CD patients as the study subjects because vitamin and mineral absorption disorders are likely to lower the BMD in these patients $[24,25]$. The exclusion criteria were refusal to provide informed consent, pregnancy or a desire to become pregnant (to protect such women from the effects of radiation exposure during DEXA scanning), cancers (especially bone cancers), and UC, Behçet disease, and other IBD such as indeterminate colitis. Patients' data such as age, disease duration and location, operation history, and treatment were recorded.

\section{Biochemical measurements}

Because bone metabolism markers are easily affected by the diet, serum samples for biochemical measurements were collected under fasting conditions [26]. This method has been described previously [23]. Briefly, the blood samples were centrifuged at $3,000 \mathrm{rpm}$ for $10 \mathrm{~min}$ at $4{ }^{\circ} \mathrm{C}$. The serum samples (top layer) were separated and stored at $-20^{\circ} \mathrm{C}$ until analysis. The serum levels of bone metabolism markers, namely ucOC, $1,25-(\mathrm{OH})_{2} \mathrm{D}, \mathrm{NTx}$, and BAP, were estimated by an electrochemiluminescence immunoassay 
(Sanko, Tokyo, Japan), radioimmunoassay (Immunodiagnostic Systems, Boldon, UK), enzyme-linked immunosorbent assay (Ostex, Seattle, WA, USA), and enzyme immunoassay (Quidel, San Diego, CA, USA), respectively. All laboratory measurements were blinded to the investigators and were performed at a special research laboratory [23].

\section{Disease assessment}

CD activity was evaluated using the CD activity index (CDAI) [27]. CDAls between 150 and 220, 220 and 450 , and $\geq 450$ indicated mild, moderate, and severe activity, respectively. The remission maintenance rate was evaluated with 150 as the cutoff CDAl. Serum C-reactive protein (CRP) level and serum albumin were measured for the assessment of $C D$ activity and the patient's nutritional status, respectively. These measurements were performed at the Laboratory Test Department of the Hamamatsu University School of Medicine.

\section{Measurement of BMD and determination of the Z-scores}

This method has been described previously [23]. Briefly, the BMD of the L2-L4 lumbar vertebrae was measured initially and 2 years later using the Discovery DXA System (Discovery A; Hologic, Bedford, MA, USA) and expressed using absolute values $\left(\mathrm{g} / \mathrm{cm}^{2}\right)$ and Z-scores [28]. The Z-scores were based on the standard deviation for the mean scores of a reference young adult sex-matched population. The $\Delta Z$-score represents the changes in the Z-scores measured initially (i.e., in the previous study) and 2 years later. Accordingly, the enrolled CD patients were divided into two groups, namely, one in which the femoral Zscore decreased (i.e., the $\Delta Z$-score $<0$ group; $n=20$ ) and one in which the femoral Z-score did not decrease (i.e., the $\Delta Z$-score $\geq 0$ group; $n=21$ ) 2 years after the initial measurement. The patients' characteristics were compared between the two groups. Furthermore, the relationship among the clinical score (CDAl), laboratory test values (CRP and albumin), and bone metabolism markers $\left(1,25-(\mathrm{OH}){ }_{2} \mathrm{D}, \mathrm{BAP}\right.$, NTx, and ucOC) was investigated in these two groups.

\section{Statistical analysis}

All statistical analyses were performed using SPSS version 24 (IBM Corp., Armonk, NY, USA) and SAS version 9.4 (SAS Institute, Cary, NC, USA). Data were expressed as mean \pm standard deviation. The chisquare test and the Fisher's exact test were used to compare the test variables between the $\Delta Z$-score $<0$ and $\Delta Z$-score $\geq 0$ groups. The correlations between two independent measurements were assessed using the Pearson's correlation coefficient: We examined the correlation between the femoral $\Delta Z$-score and the mean value of each biomarker, i.e., the CDAI (clinical score), serum albumin and CRP levels (laboratory test values), and bone metabolism markers estimated in the initial study and 2 years later. Furthermore, a multivariate regression model, including NTx and albumin, was constructed with the femoral neck $\Delta Z$ score as the predictor, and a multiple regression analysis was performed with a significance level of $5 \%$. $\mathrm{P}<0.05$ was considered as statistically significant.

\section{Results}




\section{Patient characteristics}

The patients' baseline characteristics are shown in Table 1.

Table 1

Baseline characteristics of included Crohn's disease

\begin{tabular}{|c|c|}
\hline Patients characteristics & $N=41$ \\
\hline Age at initial measurement (years old) & $38.4 \pm 9.9(20-58)$ \\
\hline Male / Female, n (\%) & $34(82.9) / 7(17.1)$ \\
\hline Age at diagnosis (years old) & $27.3 \pm 11.1(13-58)$ \\
\hline Disease duration (years) & $11.1 \pm 7.9(0-29)$ \\
\hline Smoker / non-smoker, n (\%) & 33 /8 (80.5/ 19.5) \\
\hline \multicolumn{2}{|c|}{ Age at diagnosis; $\mathrm{A} 1$ below16y, $\mathrm{A} 2$ between 17 and 40y, A3 above 40y } \\
\hline A1/ A2/ A3, n (\%) & $5(12.2) / 30(73.2) / 6(14.6)$ \\
\hline \multicolumn{2}{|c|}{ Current disease location; L1 ileal, L2 colonic, L3 ileocolonic, L4 isolated upper disease } \\
\hline L1/ L2/ L3/ L4, n (\%) & $16(39.0) / 3(7.3) / 22(53.7) / 0(0)$ \\
\hline \multicolumn{2}{|c|}{ Current disease behavior; B1 non-stricturing, non-penetrating, B2 stricturing, B3 penetratir } \\
\hline B1/ B2/ B3 & $12(29.3) / 14(34.1) / 15(36.6)$ \\
\hline $\mathrm{B} 1 / \mathrm{B} 2+\mathrm{B} 3, \mathrm{n}(\%)$ & $12(29.3) / 29(70.7)$ \\
\hline Active perianal fistula, n (\%) & $8(19.5)$ \\
\hline Previous surgery (\%), n (\%) & $18(43.9)$ \\
\hline Treatment at initial measurement, $\mathrm{n}(\%)$ & $37(90.2)$ \\
\hline 5-Aminosalicylate & $0(0)$ \\
\hline Prednisolone & $15(36.6)$ \\
\hline Immunomodulators & $25(61.0)$ \\
\hline anti-TNF a therapy & $20(48.8)$ \\
\hline Enteral nutrition & \\
\hline
\end{tabular}

\section{Disease assessment}

Among the 41 patients enrolled, 13 were undernourished with hypoalbuminemia: 9 (22.0\%) presented with albumin levels $<4.0 \mathrm{~g} / \mathrm{dL}$, whereas $4(9.8 \%)$ presented with $\leq 3.5 \mathrm{~g} / \mathrm{dL}$. There was no significant correlation between the CDAl at the beginning of the present study and the bone density of the lumbar 
spine $(P=0.5045)$ or the femoral Z-score $(P=0.3947)$ (data not shown). Furthermore, there were no significant correlations between the biomarkers and the IBD phenotype (data not shown).

\section{Comparison between the $\Delta Z$-score $<0$ and $\Delta Z$-score $\geq 0$ groups}

No significant differences in the baseline patient characteristics were observed between the two groups (Table 2). Table 3 shows a comparison of the biomarker values between the $\Delta Z$-score $<0$ and $\Delta Z$-score $\geq$ 0 groups at the initial measurement in the previous study. The mean NTx value at the first measurement was significantly higher in the $\Delta Z$-score $<0$ group than in the $\Delta Z$-score $\geq 0$ group (Table 3); however, no significant differences in the CDAl and other biomarkers levels were observed between the two groups at the first measurement; although the 1,25- $(\mathrm{OH})_{2} \mathrm{D}$ tended to be lower in the $\Delta \mathrm{Z}$-score $<0$ group, the difference was not significant. Table 4 shows the average clinical scores, laboratory test values, and bone metabolism marker levels of the first and second measurements. There were no significant differences in the serum CRP level between the $\Delta Z$-score $<0$ and $\Delta Z$-score $\geq 0$ groups. The average serum albumin level was significantly lower in the $\Delta Z$-score $<0$ group than in the $\Delta Z$-score $\geq 0$ group at both the first and second measurements. As observed during the first measurement, the mean serum NTx level during the second measurement was significantly higher in the $\Delta Z$-score $<0$ group than in the $\Delta Z$-score $\geq 0$ group. Although NTx was not a predictor of the femoral neck $\Delta Z$-score when the significance level was set to $5 \%$, it was an independent predictor when the significance level was set to $10 \%$ (data not shown). 
Table 2

Comparison of patients characteristics between $\Delta Z$-score $<0$ and $\Delta Z$-score $\geq 0$

\begin{tabular}{|c|c|c|c|}
\hline Patients characteristics & $\Delta Z$-score $<0, N=21$ & $\Delta Z$-score $\geq 0, N=20$ & $\begin{array}{l}\mathrm{P}- \\
\text { value }\end{array}$ \\
\hline $\begin{array}{l}\text { Age at initial measurement (years } \\
\text { old) }\end{array}$ & $38.3 \pm 11.4(20-58)$ & $38.5 \pm 8.4(22-55)$ & 0.96 \\
\hline Male / Female, n (\%) & $18 / 3$ & $16 / 4$ & 0.63 \\
\hline Age at diagnosis (years old) & $26.9 \pm 12.3(13-58)$ & $27.8 \pm 10.0(13-47)$ & 0.81 \\
\hline Disease duration (years) & $11.4 \pm 9.3(0-29)$ & $10.8 \pm 6.5(1-26)$ & 0.79 \\
\hline Smoker / non-smoker, n (\%) & $10(47.6) / 11 \rrbracket 52.4 \rrbracket$ & $8(40.0) / 12 \varangle 60.0 \rrbracket$ & 0.62 \\
\hline \multicolumn{4}{|c|}{ Age at diagnosis; $\mathrm{A} 1$ below16y, $\mathrm{A} 2$ between 17 and $40 \mathrm{y}, \mathrm{A} 3$ above $40 \mathrm{y}$} \\
\hline $\mathrm{A} 1 / \mathrm{A} 2 / \mathrm{A} 3$ & $\begin{array}{l}2(9.5 / 16 \otimes 76.2) / \\
3 \bigotimes 14.3 \rrbracket\end{array}$ & $3(15.0) / 14 \llbracket 70.0 \rrbracket / 3 \rrbracket 15.0$ & 0.86 \\
\hline \multicolumn{4}{|c|}{ Current disease location; L1 ileal, L2 colonic, L3 ileocolonic, L4 isolated upper disease } \\
\hline L1/ L2/ L3 & $\begin{array}{l}8(38.1) / 1 \varangle 4.8 \rrbracket / \\
12 \varangle 57.1 \rrbracket\end{array}$ & $\begin{array}{l}8(40.0) / 2 \otimes 10.0 \rrbracket / 10 \\
\otimes 50.0 \rrbracket\end{array}$ & 0.78 \\
\hline \multicolumn{4}{|c|}{ Current disease behavior; B1 non-stricturing, non-penetrating, B2 stricturing, B3 penetrating } \\
\hline B1/ B2/ B3 & $\begin{array}{l}6(28.6) / 8 \rrbracket 38.1 \rrbracket / \\
7 \rrbracket 33.3 \rrbracket\end{array}$ & $\begin{array}{l}6(30.0) / 6 \rrbracket 30.0 \rrbracket / 8 \\
\varangle 40.0 \rrbracket\end{array}$ & 0.85 \\
\hline $\mathrm{B} 1 / \mathrm{B} 2+\mathrm{B} 3$ & $6(28.6) / 15 \bigotimes 71.4 \bigotimes$ & $6(30.0) / 14 \otimes 70.0 \otimes$ & 0.92 \\
\hline Active perianal fistula, $\mathrm{n}(\%)$ & $3(14.3)$ & $5(25.0)$ & 0.39 \\
\hline Previous surgery (\%), n (\%) & $11(52.4)$ & $7(35.0)$ & 0.26 \\
\hline Treatment, n (\%) & 18(85.7) & $19(95.0)$ & 0.32 \\
\hline 5-Aminosalicylate & $0(0.0)$ & $0(0.0)$ & - \\
\hline Prednisolone & $6(28.6)$ & $9(45.0)$ & 0.27 \\
\hline Immunomodulators & 15(71.4) & $10(50.0)$ & 0.16 \\
\hline anti-TNF a therapy & $9(42.9)$ & $11(55.0)$ & 0.44 \\
\hline \multicolumn{4}{|l|}{ Enteral nutrition } \\
\hline
\end{tabular}


Table 3

Comparison of the biomarker values at initial measurement between the groups of $\Delta Z$-score less than 0 and $\Delta Z$-score more than 0

\begin{tabular}{|c|c|c|c|}
\hline & $\Delta Z$-score $<0, N=21$ & $\Delta Z$-score $\geq 0, N=20$ & P-value \\
\hline CDAl & $100.6 \pm 73.0$ & $73.8 \pm 67.9$ & 0.23 \\
\hline $\mathrm{CRP}(\mathrm{mg} / \mathrm{dL})$ & $0.39 \pm 0.64$ & $0.43 \pm 0.89$ & 0.87 \\
\hline Alb (g/dL) & $4.0 \pm 0.6$ & $4.2 \pm 0.5$ & 0.30 \\
\hline $1,25-(\mathrm{OH}) 2 \mathrm{D}(\mathrm{pg} / \mathrm{mL})$ & $54.0 \pm 14.9$ & $57.0 \pm 15.6$ & 0.53 \\
\hline BAP (U/L) & $14.4 \pm 4.0$ & $15.1 \pm 6.9$ & 0.66 \\
\hline NTx (nmolBCE/L) & $20.6 \pm 5.2$ & $17.3 \pm 3.7$ & 0.03 \\
\hline ucOC(ng/mL) & $7.6 \pm 3.1$ & $6.6 \pm 3.1$ & 0.32 \\
\hline \multicolumn{4}{|c|}{$\begin{array}{l}\text { CDAI, Crohn's disease activity index; CRP, C-reactive protein; Alb, Albumin; BAP, Bone-specific alkaline } \\
\text { phosphatase; NTx, N-terminal telopeptide of type I collagen; ucOC, Undercarboxylated osteocalcin. }\end{array}$} \\
\hline \multicolumn{4}{|c|}{ Certain data represent the mean \pm \pm standard error of mean values } \\
\hline
\end{tabular}

Table 4

Comparison of $\Delta Z$-score and the average of initial and secondary measured biomarkers values.

\begin{tabular}{|c|c|c|c|}
\hline & $\Delta Z$-score $₫ 0 \mathrm{~N}=21$ & $\Delta Z$-score $\geqq 0 N=20$ & P-value \\
\hline CDAI & $94.0 \pm 106.6$ & $64.1 \pm 63.8$ & 0.13 \\
\hline $\mathrm{CRP}(\mathrm{mg} / \mathrm{dL})$ & $0.49 \pm 0.84$ & $0.34 \pm 0.70$ & 0.37 \\
\hline Alb $(g / d L)$ & $3.9 \pm 0.7$ & $4.2 \pm 0.4$ & 0.02 \\
\hline 1,25-(OH)2D (pg/mL) & $51.3 \pm 16.4$ & $56.4 \pm 14.1$ & 0.13 \\
\hline $\mathrm{BAP}(\mathrm{U} / \mathrm{L})$ & $13.8 \pm 4.4$ & $15.1 \pm 6.2$ & 0.31 \\
\hline NTx (nmolBCE/L) & $20.5 \pm 11.1$ & $16.0 \pm 3.9$ & 0.02 \\
\hline ucOC(ng/mL) & $8.3 \pm 6.9$ & $6.8 \pm 3.0$ & 0.21 \\
\hline \multicolumn{4}{|c|}{$\begin{array}{l}\text { CDAI, Crohn's disease activity index; CRP, C-reactive protein; Alb, Albumin; BAP, Bone-specific alkaline } \\
\text { phosphatase; NTx, N-terminal telopeptide of type I collagen; ucOC, Undercarboxylated osteocalcin. }\end{array}$} \\
\hline
\end{tabular}

\section{Correlation of the $\Delta Z$-score with the CDAl, serum NTx level, and serum albumin}

The correlations between the $\Delta Z$-score and the average CDAl, serum NTx, and serum albumin levels at the first and second measurements were examined. No significant correlation was found between the mean 
CDAl and the femoral $\Delta Z$-score $(r=0.1701, P=0.2878)$ (Fig. 1a). However, a significantly negative correlation was observed between the mean serum NTx value and the femoral $\Delta Z$-score $(r=0.4180, P=$ 0.0068) (Fig. 1b). A significantly positive correlation was noted between the mean serum albumin value and the femoral $\Delta Z$-score (Fig. 1c). Although the mean NTx value was not correlated with the CDAI (P = $0.3549)$, there was a significant correlation between the mean serum albumin value and $\operatorname{CDAI}(P=0.0042$, $r=0.4377)$.

\section{Relationship between anti-TNF-a therapy and serum NTx value}

We evaluated the relationship between anti-TNF-a therapy and the NTx value. In the anti-TNF-a administration group, the NTx value was significantly lower at the second measurement than at the first measurement (Fig. 2). However, in the anti-TNF-a non-administration group, the NTx value did not differ significantly between the first and second measurements.

\section{Relation between anti-TNF- $a$ therapy and the Z-score}

We compared the 2-year changes in the femoral Z-score between the anti-TNF- $a$ administration and nonadministration groups. Although the femoral neck Z-score at the first measurement tended to be lower in the anti-TNF-a administration group than in the non-administration group, this difference was not significant $(P=0.4390)$ (Fig. 3a). Furthermore, although the femoral neck Z-score at the second measurement tended to be lower in the anti-TNF-a administration group than in the non-administration group, this was not significant either $(P=0.9219)$ (Fig. 3b). Although the $\Delta Z$-score tended to decrease in the anti-TNF- $a$ administration group, there was no significant difference when compared to the score in the anti-TNF-a non-administration group during the 2-year observation period $(P=0.8556)$.

\section{Discussion}

This study investigated whether an elevated serum NTx level is a risk predictor of osteoporosis in patients with CD. Results showed the BMD decreased in 20 (48.8\%) of the enrolled 41 CD patients over a period of 2 years. When the CDAl, CRP and albumin levels, and bone metabolism markers were examined in the $\Delta Z$ score $<0$ and $\Delta Z$-score $\geq 0$ groups, only the NTx value was observed to be significantly higher at the first measurement in the $\Delta Z$-score $<0$ group.

The association between IBD patients and osteoporosis has been reported previously [1-8]. Furthermore, we have previously reported that compared with healthy individuals and UC patients, CD patients have a lower BMD and higher levels of bone metabolism markers [23]. In the present study, we observed that among the bone metabolism markers analyzed (BAP, NTx, and ucOC), only the bone resorption marker (NTx) was elevated; this can be explained as follows. There are two major causes of osteoporosis in CD. The first is the relationship between inflammatory cytokines and the RANK (receptor activator of NF$\mathrm{K} \beta$ )/RANKL (RANK ligand)/OPG system, and the second is the decreased absorption of vitamin D from 
the intestinal tract. Homeostasis of bone metabolism is generally maintained by the balance among RANK, bone resorption, and RANKL inhibition [29, 30]. In IBD, the activated T cells strongly express RANKL, which differentiates and induces the osteoclasts via RANK, leading to bone resorption. This mechanism decreases the BMD in IBD patients, thereby promoting bone resorption in the process. Therefore, of the three bone metabolism markers examined in this study, only the bone resorption marker, NTx, was significantly higher in the $\Delta Z$-score $<0$ group than in the $\Delta Z$-score $\geq 0$ group at the first measurement. The mean NTx value at the first and second measurements were also significantly higher in the $\Delta Z$-score $<0$ group than in the $\Delta Z$-score $\geq 0$ group.

Although the serum albumin level did not differ significantly between the $\Delta Z$-score $<0$ and $\Delta Z$-score $\geq 0$ groups, the average serum albumin level at the first and second measurements in the $\Delta Z$-score $<0$ group was significantly lower than in the $\Delta Z$-score $\geq 0$ group. This suggests that the nutritional decline in $C D$ is related to BMD decline. Afshinnia et al. [21] reported that hypoalbuminemia is an independent risk factor for osteoporosis and that a longer duration of hypoalbuminemia carries a higher risk of osteoporosis. Our findings support that hypoalbuminemia increases the risk of osteoporosis in CD patients, as hypoalbuminemia tends to persist over time. Factors that decrease the nutritional status in CD patients include an increased metabolism due to inflammation, leakage of nutrients from the intestine, and malabsorption.

Therefore, based on the above results, we examined the correlation of serum NTx and albumin with the $\Delta Z$-score in order to verify whether these are related to BMD decline over time. In this study, changes in the Z-score were shown to correlate with the serum NTx and albumin levels, indicating that these could function as predictors of BMD decline in $C D$ patients. Conversely, there were no significant differences in the serum CRP levels between the $\Delta Z$-score $<0$ and $\Delta Z$-score $\geq 0$ groups. Although in vitro and animal studies suggest that inflammatory cytokines affect $B M D$, there is insufficient evidence on the relationship between the two in CD patients [31-33]. Although there are differences in the study conditions, some reports have indicated a relationship between the CRP level and BMD, whereas others have indicated that increased concentrations of inflammatory biomarkers are not a risk factor for BMD reduction; therefore, an effective consensus has not been achieved [34-37]. In this study, because CRP levels tended to be higher in the $\Delta Z$-score < 0 group, we speculate that the BMD may have decreased due to an inflammatory reaction.

IBD patients, especially CD patients, are prone to malnutrition due to nutrient leakage from the intestine, small intestinal lesions, and intestinal complications. Vitamin $D$ is required for efficient absorption of calcium from the intestinal tract, and it is well-known that patients with $C D$ are prone to vitamin $D$ deficiency $[38,39]$. Although the $1,25-(\mathrm{OH})_{2} \mathrm{D}$ levels did not differ significantly between the $\Delta Z$-score $<0$ and $\Delta Z$-score $\geq 0$ groups, they tended to be lower in the former.

Several reports have stated that IFX administration could improve the levels of bone metabolism biomarkers [40-42]. Veerappan et al. [43] reported that adalimumab had a beneficial effect on bone metabolism, similar to IFX. We previously showed that serum NTx levels were significantly higher in CD 
patients receiving IFX than in CD patients who were not [23]. In this study, we evaluated the effects of an anti-TNF-a therapy (involving not only IFX, but also adalimumab as anti-TNF-a preparations) on bone metabolism biomarkers. The NTx level significantly decreased after 2 years in CD patients who did not receive the anti-TNF-a therapy; this may be related to the deterioration of bone metabolism. Conversely, the NTx levels did not decrease significantly over the course of 2 years in CD patients who received the anti-TNF-a therapy. Therefore, anti-TNF-a therapy may contribute to the maintenance of BMD, possibly by suppressing the decrease in serum NTx indirectly. Ryan et al. [44] estimated the NTx level for bone metabolism in CD patients after IFX administration. They reported that although IFX administration did not induce a significant change in the NTx value 4 months after treatment initiation, there was a significant decrease in the NTx value after 16 months, contrary to the results of our study. This may be due to differences in the disease activity and in the period of anti-TNF- $a$ administration. A further investigation into the same is necessary. Although the detailed mechanism is unclear, it is believed that bone resorption in $\mathrm{CD}$ patients is impaired; therefore, these abnormalities have some influence on the decrease in NTx levels. Based on these considerations and the results of this study, we speculate that anti-TNF-a preparations indirectly suppressed the decrease in NTX.

Furthermore, the measurement of NTx as a marker of bone resorption is important in a variety of diseases. Interestingly, we previously reported that serum NTx levels were elevated in CD but not in UC, despite both being an IBD [23]. The difference between CD and UC (or other diseases that cause abnormal bone metabolism) is that CD is associated with a deficiency in the absorption of bone-related nutrients and minerals from the small intestine. Furthermore, previous studies have reported that $C D$ is associated with a higher risk of osteoporosis than UC [24]; the presence of small bowel lesions in CD patients impairs the absorption of vitamin $\mathrm{D}$ or calcium.

There are some limitations to this study. First, the number of patients included was small; only 20 and 21 patients assessed in the two groups. Second, the bone metabolism markers were measured over a relatively short-term period of 2 years; therefore, a long-term evaluation is necessary. Because bone metabolism is expected to change over a long period of time, measurements over a longer period are preferred in this study.

\section{Conclusion}

Elevated serum NTx could be a useful predictor of femoral BMD loss in patients with CD. Prolonged malnutrition could also be a risk factor for femoral BMD loss. Moreover, anti-TNF-a therapy maintained an elevated serum NTx level, suggesting that treatment with anti-TNF-a may help control the increased bone resorption in $\mathrm{CD}$ patients.

\section{Abbreviations}

1,25-(OH $)_{2} \mathrm{D}, 1,25$-dihydroxyvitamin $\mathrm{D}$ 
BMD, bone mineral density

CD, Crohn disease

CDAl, Crohn's Disease Activity Index

$\mathrm{Cl}$, confidence interval

DEXA, dual-energy X-ray absorptiometry

IBD, inflammatory bowel disease

IFX, infliximab

NTx, N-terminal telopeptide of type I collagen

UC, ulcerative colitis

ucOC, undercarboxylated osteocalcin

\section{Declarations}

Ethical approval and consent to participate: The study protocol was reviewed and approved by the Institutional Review Board of Hamamatsu University School of Medicine (16-246). The investigation was conducted in accordance with Good Clinical Practice principles in adherence to the Declaration of Helsinki. Written informed consent was obtained from all individual participants included in the study.

Consent for publication: Not applicable

Availability of data and material: Not applicable

Competing interests: The authors declare that they have no competing interests.

Funding: No external funding was received for this study.

Authors' contributions: $\mathrm{NI}$ designed and analyzed the data. NI, TM, TH, RT, SaT, ShT, TK, MY, MI, YH, OS, and TF analyzed the data and contributed to the preparation of the manuscript. KS designed the study, acquired, analyzed, and interpreted the data, and prepared the manuscript.

Acknowledgments: Not applicable.

\section{References}

1. Bernstein CN, Leslie WD, Leboff MS. AGA technical review on osteoporosis in gastrointestinal diseases. Gastroenterology. 2003;124:795-841. 
2. Ghosh S, Cowen S, Hannan WJ. Low bone mineral density in Crohn's disease, but not in ulcerative colitis, at diagnosis. Gastroenterology. 1994;107:1031-9.

3. Ardizzone S, Bollani S, Bettica P, Bevilacqua M, Molteni P, Bianchi Porro G. Altered bone metabolism in inflammatory bowel disease: there is a difference between Crohn's disease and ulcerative colitis. $\mathrm{J}$ Intern Med. 2000;247:63-70.

4. Targownik LE, Bernstein CN, Nugent Z, Leslie WD. Inflammatory bowel disease has a small effect on bone mineral density and risk for osteoporosis. Clin Gastroenterol Hepatol. 2013;11:278-85.

5. Sinnott B, Licata A. Assessment of bone and mineral metabolism in inflammatory bowel disease: case series and review. Endocr Pract. 2006;12:622-9.

6. Loftus EV Jr, Achenbach SJ, Sandborn WJ, Tremaine WJ, Oberg AL, Melton LJ III. Risk of fracture in ulcerative colitis: a population-based study from Olmsted County, Minnesota. Clin Gastroenterol Hepatol. 2003;1:465-73.

7. Ali T, Lam D, Bronze MS, Humphrey MB. Osteoporosis in inflammatory bowel disease. Am J Med. 2009;122:599-604.

8. Pollak RD, Karmeli F, Eliakim R, Ackerman Z, Tabb K, Rachmilewitz D. Femoral neck osteopenia in patients with inflammatory bowel disease. Am J Gastroenterol. 1998;93:1483-90.

9. Bernstein CN, Blanchard JF, Leslie W, Wajda A, Yu BN. The incidence of fracture among patients with inflammatory bowel disease: a population-based cohort study. Ann Intern Med. 2000;133:795-9.

10. Lewiecki EM, Borges JL. Bone density testing in clinical practice. Arq Bras Endocrinol Metabol. 2006;50:586-95.

11. Kanis JA, Glüer CC for the Committee of Scientific Advisors, International Osteoporosis Foundation. An update on the diagnosis and assessment of osteoporosis with densitometry. Osteoporos Int. 2000;11:192-202.

12. Baim S, Leonard MB, Bianchi ML, Hans DB, Kalkwarf HJ, Langman CB, et al. Official positions of the International Society for Clinical Densitometry and executive summary of the 2007 ISCD Pediatric Position Development Conference. J Clin Densitom. 2008;11:6-21.

13. Tkatch L, Rapin CH, Rizzoli R, Slosman D, Nydegger V, Vasey H, et al. Benefits of oral protein supplementation in elderly patients with fracture of the proximal femur. J Am Coll Nutr. 1992;11:519-25.

14. Cabral HW, Andolphi BF, Ferreira BV, Alves DCF, Morelato RL, Chambo FA, et al. The use of biomarkers in clinical osteoporosis. Rev Assoc Med Bras. 2016;62:368-76.

15. Garnero P. The utility of biomarkers in osteoporosis management. Mol Diagn Ther. 2017;21:401-18.

16. Eastell R, Mallinak N, Weiss S, Ettinger M, Pettinger M, Cain D, et al. Biological variability of serum and urinary $\mathrm{N}$-telopeptides of type I collagen in postmenopausal women. J Bone Miner Res. 2000;15:594-8.

17. Szulc P, Meunier PJ. Is vitamin K deficiency a risk factor for osteoporosis in Crohn's disease? Lancet. 2001;357:1995-6. 
18. Hamano T. [Bone and bone related biochemical examinations. Bone and collagen related metabolites. Urinary and serum NTX as bone resorption markers.]. Clin Calcium. 2006;16:987-92.

19. Von Lampe B, Barthel B, Coupland SE, Riecken EO, Rosewicz S. Differential expression of matrix metalloproteinases and their tissue inhibitors in colon mucosa of patients with inflammatory bowel disease. Gut. 2000;47:63-73.

20. Meijer MJ, Mieremet-Ooms MA, Sier CF, Van Hogezand RA, Lamers CB, Hommes DW, et al. Matrix metalloproteinases and their tissue inhibitors as prognostic indicators for diagnostic and surgical recurrence in Crohn's disease. Inflamm Bowel Dis. 2009;15:84-92.

21. Afshinnia F, Wong KK, Sundaram B, Ackermann RJ, Pennathur S. Hypoalbuminemia and osteoporosis: reappraisal of a controversy. J Clin Endocrinol Metab. 2016;101:167-75.

22. Afshinnia F, Pennathur S. Association of hypoalbuminemia with osteoporosis: analysis of the National Health and Nutrition Examination Survey. J Clin Endocrinol Metab. 2016;101:2468-74.

23. Sugimoto K, Ikeya K, lida T, Kawasaki S, Arai O, Umehara K, et al. An increased serum N-terminal telopeptide of Type I collagen, a biochemical marker of increased bone resorption, is associated with infliximab therapy in patients with Crohn's Disease. Dig Dis Sci. 2016;61:99-106.

24. Leichtmann GA, Bengoa JM, Bolt MJ, Sitrin MD. Intestinal absorption of cholecalciferol and 25hydroxycholecalciferol in patients with both Crohn's disease and intestinal resection. Am J Clin Nutr. 1991;54:548-52.

25. Carter MJ, Lobo AJ, Travis SP. British Society of Gastroenterology guidelines for inflammatory bowel disease. Gut. 2004;53:v1-16.

26. Delmas PD, Eastell R, Garnero P, Seibel MJ, Stepan J, Committee of Scientific Advisors of the International Osteoporosis Foundation. The use of biochemical markers of bone turnover in osteoporosis. Osteoporos Int Suppl. 2000;6:2-17.

27. Best WR, Becktel JM, Singleton JW, Kern F Jr. Development of a Crohn's disease activity index: National Cooperative Crohn's Disease Study. Gastroenterology. 1976;70:439-44.

28. Kanis JA, Adachi JD, Cooper C, Clark P, Cummings SR, et al. Standardising the descriptive epidemiology of osteoporosis: recommendations from the Epidemiology and Quality of Life Working Group of IOF. Osteoporos Int. 2013;24:2763-4.

29. Theill LE, Boyle WJ, Penninger JM. RANK-L and RANK: T cells, bone loss, and mammalian evolution. Annu Rev Immunol. 2002;20:795-823.

30. Tilg H, Moschen AR, Kaser A, Pines A, Dotan I. Gut, inflammation and osteoporosis: basic and clinical concepts. Gut. 2008;57:684-94.

31. Ammann P, Rizzoli R, Bonjour JP, Bourrin S, Meyer JM, Vassalli P, et al. Transgenic mice expressing soluble tumor necrosis factor-receptor are protected against bone loss caused by estrogen deficiency. J Clin Invest. 1997;99:1699-703.

32. Oelzner P, Franke S, Müller A, Hein G, Stein G. Relationship between soluble markers of immune activation and bone turnover in post-menopausal women with rheumatoid arthritis. Rheumatology. 1999;38:841-7. 
33. Matsuno H, Yudoh K, Katayama R, Nakazawa F, Uzuki M, Sawai T, et al. The role of TNF-alpha in the pathogenesis of inflammation and joint destruction in rheumatoid arthritis (RA): a study using a human RA/SCID mouse chimera. Rheumatology. 2002;41:329-37.

34. de Pablo P, Cooper MS, Buckley CD. Association between bone mineral density and C-reactive protein in a large population-based sample. Arthritis Rheum. 2012;64:2624-31.

35. Huang JV, Schooling CM. Inflammation and bone mineral density: a Mendelian randomization study. Sci Rep. 2017;7:1-7.

36. Sponholtz TR, Zhang X, Fontes JD, Meigs JB, Cupples LA, Kiel DP, et al. Association between inflammatory biomarkers and bone mineral density in a community-based cohort of men and women. Arthritis Care Res (Hoboken). 2014;66:1233-40.

37. Coqueiro FG, Rocha R, Menezes CA, Lopes MB, Oliveira VR, Fortes FM, et al. What nutritional factors influence bone mineral density in Crohn's disease patients? Intest Res. 2018;16:436-44.

38. Driscoll RH Jr, Meredith SC, Sitrin M, Rosenberg IH. Vitamin D deficiency and bone disease in patients with Crohn's disease. Gastroenterology. 1982;83:1252-8.

39. Sentongo TA, Semaeo EJ, Stettler N, Piccoli DA, Stallings VA, Zemel BS. Vitamin D status in children, adolescents, and young adults with Crohn disease. Am J Clin Nutr. 2002;76:1077-81.

40. Franchimont N, Putzeys V, Collette J, Vermeire S, Rutgeerts P, De Vos M, et al. Rapid improvement of bone metabolism after infliximab treatment in Crohn's disease. Aliment Pharmacol Ther. 2004;20:607-14.

41. Abreu MT, Geller JL, Vasiliauskas EA, Kam LY, Vora P, Martyak LA, et al. Treatment with infliximab is associated with increased markers of bone formation in patients with Crohn's disease. $\mathrm{J}$ Clin Gastroenterol. 2006;40:55-63.

42. Thayu M, Leonard M, Hyams J, Crandall W, Kugathasan S, Otley A, et al. Improvement in a biomarker of bone formation during infliximab therapy in pediatric Crohn disease: results of the REACH study. Bone. 2007;40:81.

43. Veerappan SG, Healy M, Walsh BJ, O'Morain CA, Daly JS, Ryan BM. Adalimumab therapy has a beneficial effect on bone metabolism in patients with Crohn's disease. Dig Dis Sci. 2015;60:2119-29.

44. Ryan BM, Russel MG, Schurgers L, Wichers M, Sijbrandij J, Stockbrugger RW, et al. Effect of antitumour necrosis factor-a therapy on bone turnover in patients with active Crohn's disease: a prospective study. Aliment Pharmacol Ther. 2004;20:851-7.

\section{Figures}



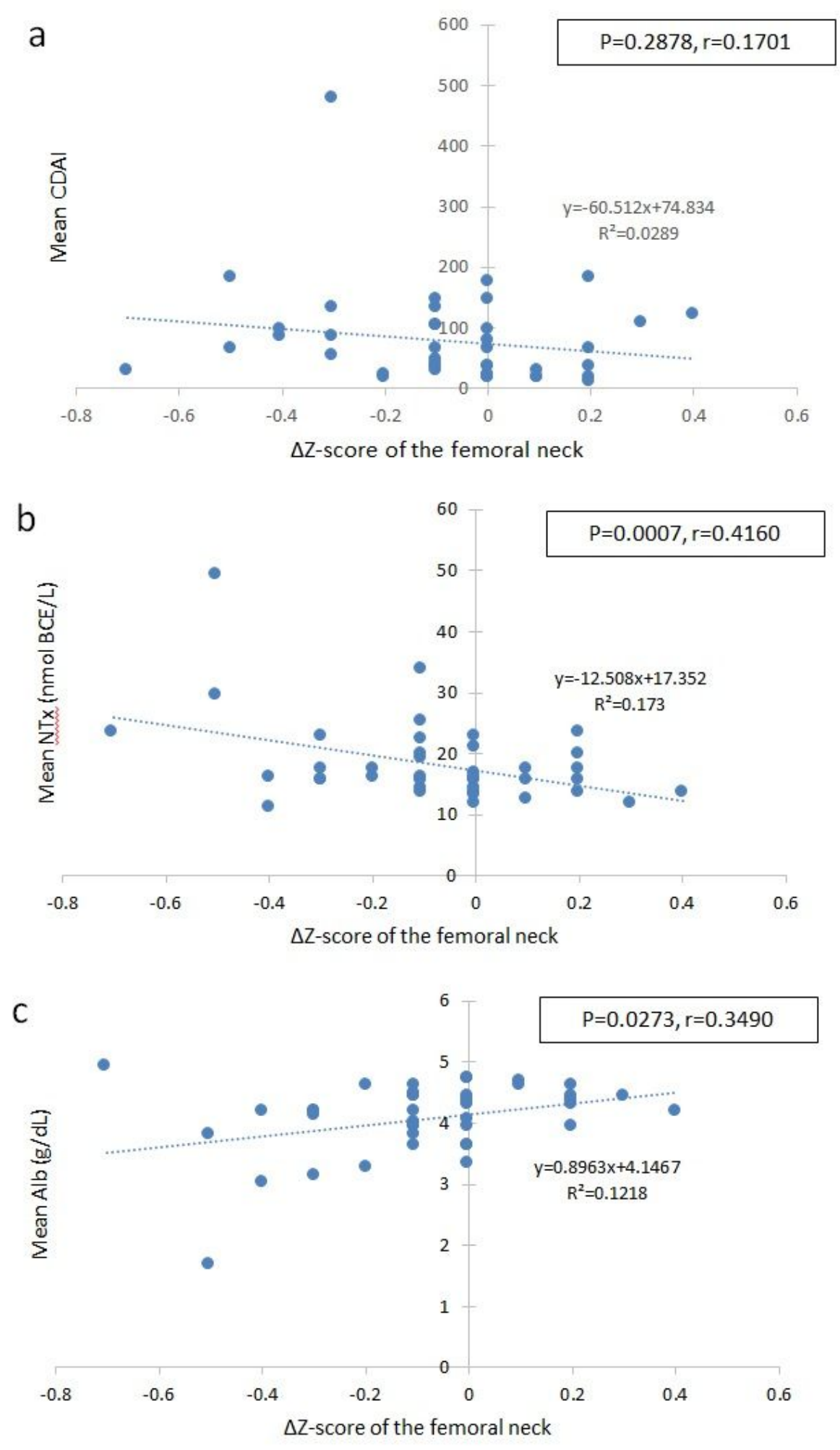

\section{Figure 1}

Correlation between the femoral neck $\Delta Z$-score and the mean biomarker levels. (a) Scatter plots of the femoral neck $\Delta Z$-score and the mean CDAl (a), mean NTx (b), and (c) mean Alb. CDAl, Crohn's Disease Activity Index; NTx, serum N-terminal telopeptide of type I collagen; Alb, albumin. 


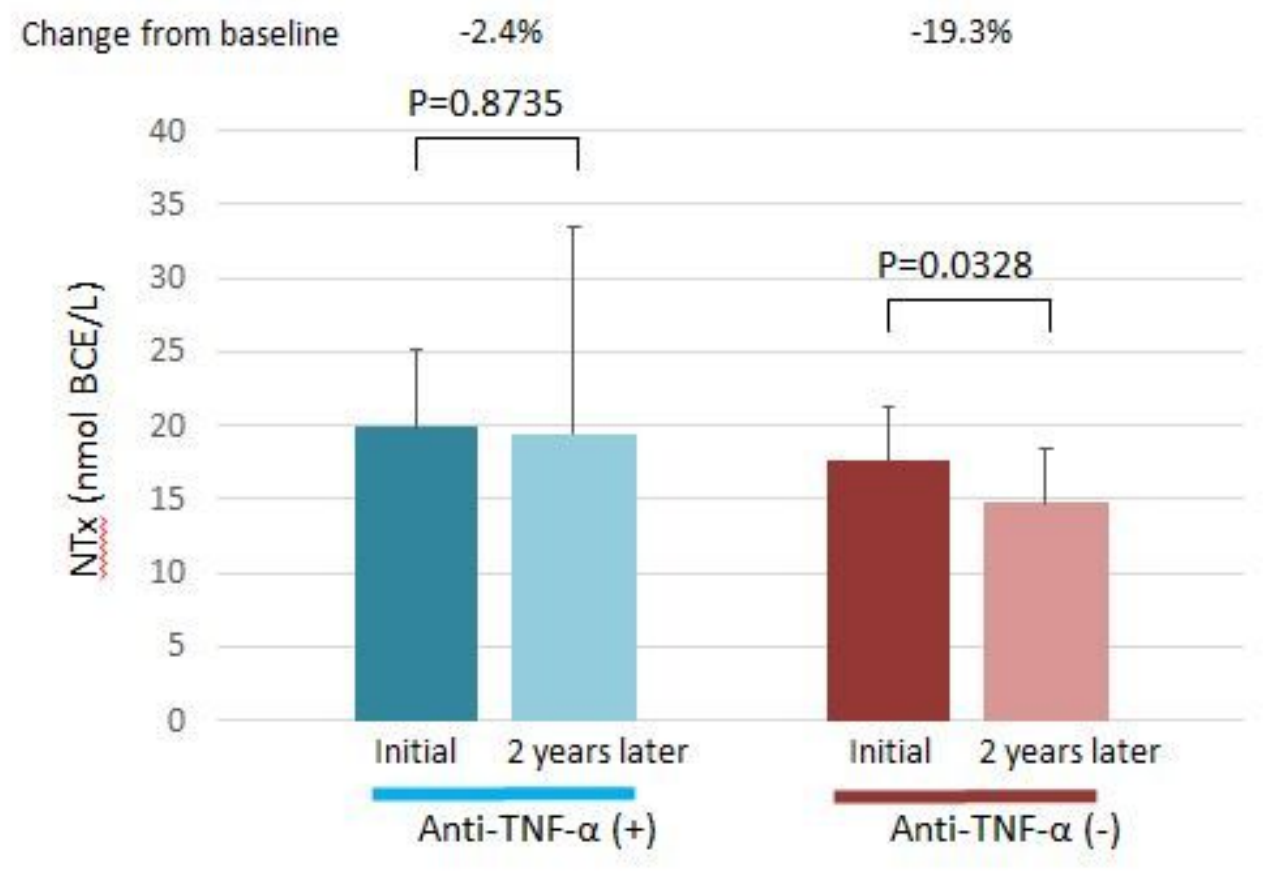

\section{Figure 2}

Serum NTx levels in the anti-TNF- $a$ administration and non-administration groups. The serum NTx levels at the first measurement and 2 years later are shown for each group. NTx, N-terminal telopeptide of type I collagen; TNF-a, tumor necrosis factor $a$. 

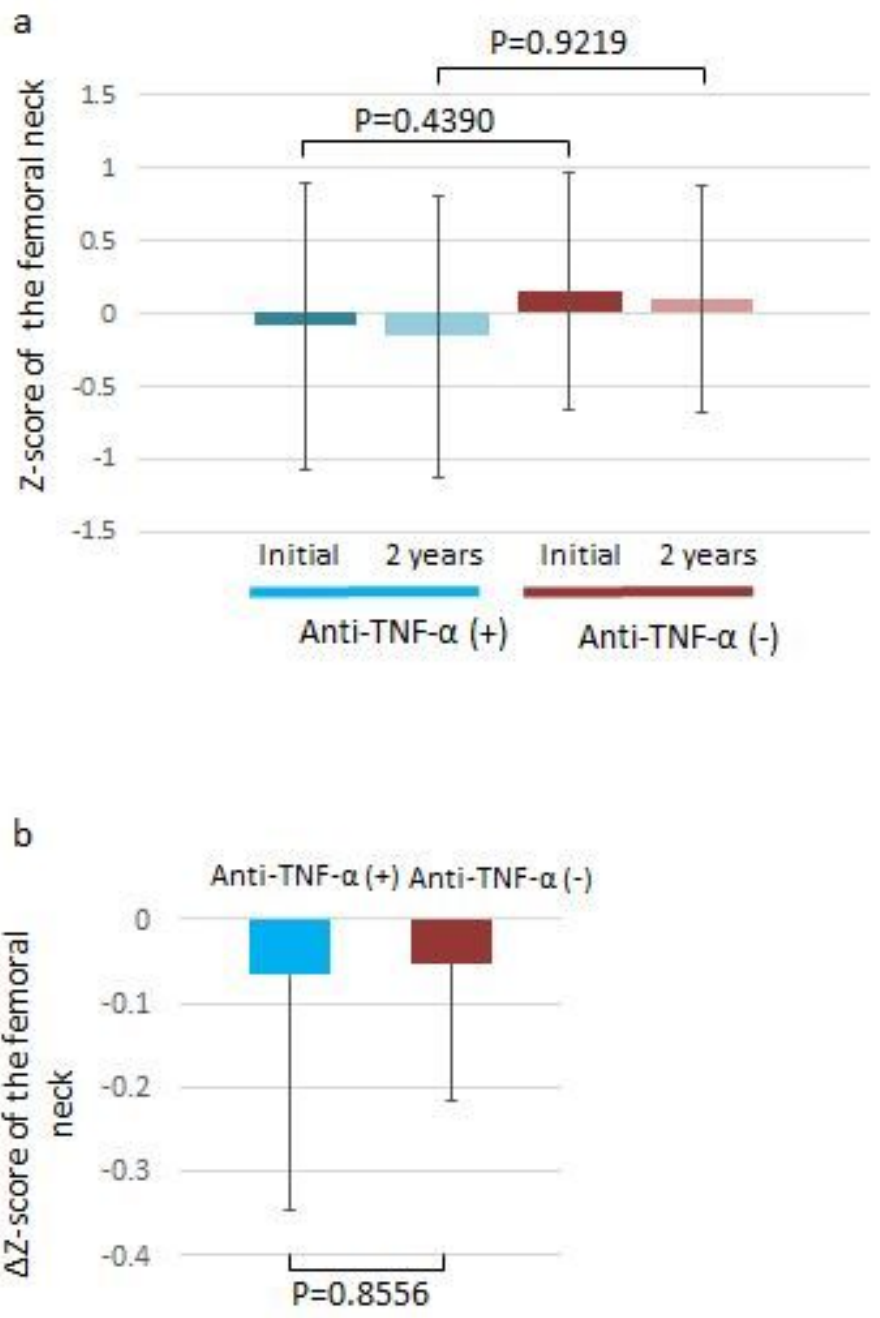

\section{Figure 3}

Change in the Z- and $\Delta Z$-scores of the femoral neck. (a) Femoral neck Z-scores of the anti-TNF-a administration and non-administration groups at the first measurement and 2 years later. (b) Femoral neck $\Delta Z$-scores of the anti-TNF- $a$ administration and non-administration groups. TNF-a, tumor necrosis factor a. 